\title{
Disturbed nights and 3-4 month old infants: the effects of feeding and thermal environment
}

\author{
M P Wailoo, S A Petersen, H Whitaker
}

\begin{abstract}
Parents completed a prospective diary of a night's sleep for 87, 3-4 month old infants at home whose body temperatures were continuously recorded. We found that about half of the babies disturbed their parents in the night. Breast fed babies were more likely to wake parents in the middle of the night. The babies who disturbed their parents in the middle of the night were significantly more heavily wrapped in significantly warmer rooms. We suggest that discomfort from efforts at active thermoregulation in warm environments may lead some babies to disturb their parents at 'unsocial hours'.
\end{abstract}

Many 3-4 month old infants wake during the night, and are often assumed to be uncomfortable in some way. Hunger may be a cause, and recent reports that breast fed babies wake more often $^{1}$ would appear to partly substantiate this suggestion. They may also be wet, or be awoken by snoring or colic. ${ }^{2}$ One factor that has not been examined is thermal comfort. Many 3-4 month old infants are found to be sweating in their cots, ${ }^{3}$ suggesting that active cooling is necessary during quiet sleep in order to maintain a normal body temperature, certainly during the early parts of the night. It may be that the combined thermal effects of clothing and wrapping, and ambient temperature, ${ }^{3}$ make it difficult to lose body heat, create a need for active thermoregulation, and impose a sufficient stress to wake the infant.

In a recent study we recorded body and environmental temperatures in 3-4 month old infants during a normal night's sleep at home, and in addition parents maintained detailed diaries of sleep and feeding patterns. This report examines the effects of feeding and thermal environment.

Subjects and methods

University of Leicester, Department of Child Health M P Wailoo H Whitaker Department of Physiology $S$ A Petersen

Correspondence to: Dr M P Wailoo, Department of Child Health Clinical Sciences Building, Leicester Royal Infirmary, O Box 65,

Leicester LE2 7LX.

Accepted 25 January 1990 tinuously at four sites: the rectum, the skin surface on the abdomen $(3 \mathrm{~cm}$ to the left of the umbilicus), skin surface on the forehead, as well as the ambient temperature in the room. The probes were connected to a Grant Squirrell Data
Ninety eight normal full term babies were recruited at birth, and full perinatal data recorded. Arrangements were then made for a researcher to record body temperature continuously over a single night between the ages of 3 and 4 months. At this stage each baby was weighed and skinfold thickness measured, and
probes affixed to record temperature con-
Logger (Grants Instruments, Cambridge) set to record temperatures at one minute intervals throughout the night. A full description was recorded of the items of clothing and wrapping around the baby so that a 'tog' value could be calculated.

Parents were asked to keep a full diary during the night, including times that the infant woke, was fed, and nappy changed, etc. They were asked to be particularly careful to record accurately. As the monitoring was for only one night, we are confident that most instances of waking were recorded. Information was also recorded on any recent illnesses of the baby or in the household, and the baby checked for any signs of minor illness on the day of recording.

All the measurements were taken during December to March during the cold winter of 1986, when the minimum outside temperature fell as low as $-9^{\circ} \mathrm{C}$ and averaged only $0^{\circ} \mathrm{C}$.

After monitoring, the computerised data on each baby were extracted to show a minute by minute record over the night, and scrutinised for problems such as loss of probes. Only unblemished records were analysed further.

\section{Results}

SUBJECTS

Adequate data were collected on 87 babies, though only 74 had complete temperature records. They ranged in age from $9 \cdot 5$ to $19 \cdot 5$ weeks (standardised to a 40 week gestation), with a mean age of 14.9 weeks. All but seven were aged between 12 and 18 weeks. The body weight at monitoring averaged 6265 (80) g (range $4520-8100 \mathrm{~g}$ ), and the birth weight 3257 (50) $\mathrm{g}$. All babies were well at the time of the study.

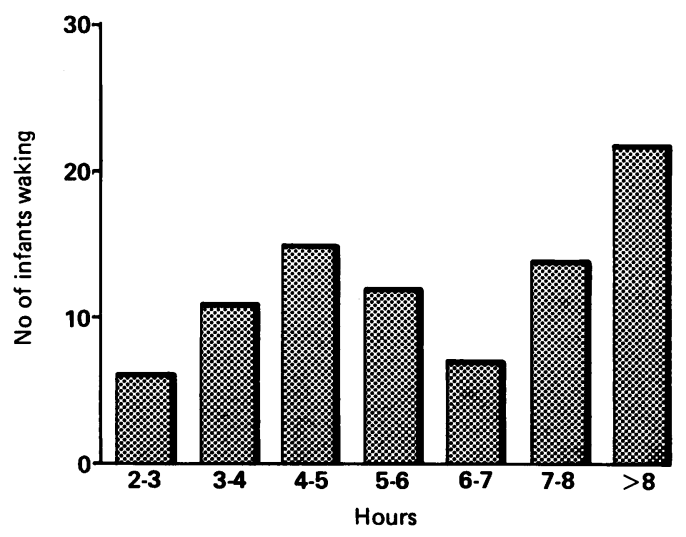

Figure 1 Waking pattern of infants at night $(n=87)$. 
PARENTAL DISTURBANCE

Twenty two of the 87 babies did not disturb their parents for at least eight hours. Sixty five woke at least once, of whom 17 disturbed their parents twice, and eight three times or more. Although five woke within the first hour we considered these as 'failure to settle', and deemed the night to begin when they were returned to their cots.

The median time to first parental disturbance was $6 \cdot 1$ hours, though there was a greater tendency to wake between three and six hours and after seven hours or more (fig 1). Sleeping pattern was unrelated to age, birth weight, or body weight.

PARENTAL DISTURBANCE AND FEEDING

Forty four babies were breast fed at birth, but only 17 were still being breast fed at the time of the monitoring.

All the babies were fed at bedtime. On 56 of the 99 times they disturbed parents during the night they were fed. The proportion of wakers who were fed varied significantly over the night, being greater later (table, $\chi^{2}=7 \cdot 8$ with $3 \mathrm{df}$, $\mathrm{p}<0.01$ )

Babies who were breast fed were more likely to disturb their parents within four hours $\left(\chi^{2}=\right.$ 5.9 with $3 \mathrm{df}, \mathrm{p}<0.01)$, though they did not wake more often than artificially fed babies.

\section{PARENTAL DISTURBANCE AND THERMAL}

\section{ENVIRONMENT}

There were significant associations between thermal environment and waking pattern of the babies. Those who woke earliest were lightly clad in cool rooms, but in the fourth and fifth hour the room temperature at the time of waking was significantly higher for those who disturbed their parents than those who did not $(p<0.05$, Student's $t$ test). Those disturbing their parents in the fourth hour were also significantly more heavily wrapped $(\mathrm{p}<0.05$, Student's $t$ test).

Babies who disturbed their parents more than once were significantly more heavily wrapped than those who slept through or woke only once $(\mathrm{p}<0.01$, Student's $t$ test).

\section{BODY TEMPERATURE}

At the time of parental disturbance the rectal temperature of the babies was significantly higher than that of those who were still apparently asleep ( $p<0.05$, Student's $t$ test). If the

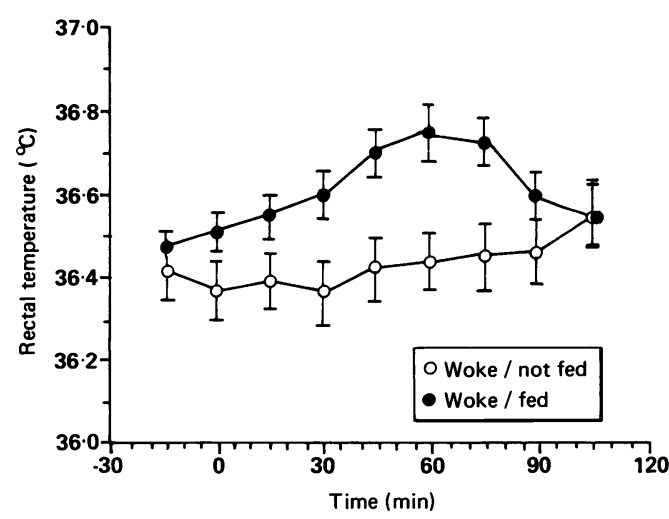

Figure 2 Rectal temperature in infants related to feeding and waking.

baby was not fed, rectal temperature fell again within 30 minutes, but those who were fed showed a small rise of rectal temperature for an hour or so (fig 2). Babies fed late in the night were not included in the figure as they would have been warming anyway at the time. ${ }^{4}$

Forty three of the babies were observed to be sweating at the time they disturbed their parents. There were non-significant trends for the babies who were sweating to wake earlier and more often.

\section{Discussion}

Most of the 3-4 month old infants in this study disturbed their parents within eight hours of bedtime, with about half waking in the small hours. This level of wakefulness exceeds that reported by Eaton-Evans and Dugdale in a retrospective analysis over a longer period. ${ }^{1}$ There were probes attached to our babies, but we have no evidence that they led to any additional disturbance.

Breast feeding, reported by others as a cause of frequent waking, ${ }^{15}$ was also associated with early disturbance of parents in our study, though breast fed babies did not wake more often. The fact that artificially fed babies are less likely to disturb parents in 'unsocial' hours may be one of the reasons why so many of our parents gave up breast feeding in the first months. Perhaps a bottle at night time might reduce this problem.

The few babies who woke very early were poorly wrapped in cool rooms, though their body temperatures were not low. The larger number who woke four or five hours after bedtime were, however, the more heavily wrapped individuals in warmer rooms. Heavily wrapped

Factors related to sleeping patterns in 3-4 month old infants

\begin{tabular}{|c|c|c|c|c|c|c|c|}
\hline & \multicolumn{3}{|l|}{ Hours sleep } & \multirow[b]{2}{*}{$5-6$} & \multirow[b]{2}{*}{$6-7$} & \multirow[b]{2}{*}{$7-8$} & \multirow[b]{2}{*}{$>8$} \\
\hline & $2-3$ & $3-4$ & $4-5$ & & & & \\
\hline \multirow{4}{*}{$\begin{array}{l}\text { No of babies waking } \\
\text { No fed } \\
\text { Breast fed on waking (total } \\
\text { breast fed) } \\
\text { No artificially fed/No actually fed on } \\
\text { waking } \\
\text { Mean (SEM) room temperature }\left({ }^{\circ} \mathrm{C} \text { ) }\right. \\
\text { Mean (SEM) insulation, clothing, } \\
\text { and wrapping (tog units) }\end{array}$} & $\begin{array}{l}6 \\
\mathbf{3}\end{array}$ & $\begin{array}{r}11 \\
4\end{array}$ & $\begin{array}{r}15 \\
8\end{array}$ & $\begin{array}{l}12 \\
10\end{array}$ & $\begin{array}{l}7 \\
6\end{array}$ & $\begin{array}{l}14 \\
14\end{array}$ & $\begin{array}{l}22 \\
22\end{array}$ \\
\hline & $1(1)$ & $1(3)$ & $3(4)$ & $4(4)$ & $0(0)$ & $1(1)$ & $1(1)$ \\
\hline & $\begin{array}{l}5 / 2 \\
10 \cdot 3(1 \cdot 3)\end{array}$ & $\begin{array}{l}8 / 3 \\
16(1 \cdot 2)\end{array}$ & $\begin{array}{l}11 / 5 \\
16 \cdot 7(1 \cdot 1)\end{array}$ & $\begin{array}{l}8 / 6 \\
14 \cdot 05(1 \cdot 3)\end{array}$ & $\begin{array}{l}7 / 6 \\
14 \cdot 1(1 \cdot 2)\end{array}$ & $\begin{array}{l}13 / 13 \\
12 \cdot 2(1 \cdot 6)\end{array}$ & $\begin{array}{l}21 / 21 \\
12.6(0.8)\end{array}$ \\
\hline & $12 \cdot 4(1 \cdot 3)$ & $16 \cdot 4(2 \cdot 1)$ & $14 \cdot 9(1 \cdot 3)$ & $12 \cdot 9(0 \cdot 7)$ & $14 \cdot 6(2 \cdot 6)$ & $13.5(0.9)$ & $15 \cdot 1(1 \cdot 0)$ \\
\hline
\end{tabular}


babies also woke more often. The fact that many were observed to be sweating is an indication that their disturbance may be, in part, attributable to being uncomfortably warm. Rectal temperature was, however, only raised for a few minutes around the time of waking, presumably because of activity. Unless babies were fed at this time, rectal temperature returned rapidly to that of the undisturbed state. Feeding was associated with a raised rectal temperature for an hour or so, presumably because of the mass action of the food. The thermal environment of babies who woke later in the night was not different from that of undisturbed infants who were fed on waking. Hunger could be an important factor at this time.

Parents are most likely to be disturbed in the most unsocial hours if their babies are breast fed and kept well wrapped in warm rooms. A supplementary bottle at bedtime, less wrapping, and somewhat cooler rooms should allow parents a better night's sleep, and might even persuade some mothers to persevere with breast feeding.

We thank the Foundation for the Study of Infant Death for support.

1 Eaton-Evans J, Dugdale AE. Sleep patterns of infants in the first year of life. Arch Dis Child 1988;63:647-9.

2 Weissbluth M, Davies AI Poacher J. Night waking in 4-8 month old infants. F Pediatr 1984;104:477-80.

3 Wailoo MP, Petersen SA, Whitaker H, Goodenough P. The thermal environment in which 3-4 month old infants sleep at home. Arch Dis Child 1989;64:1516.

4 Wailoo MP, Petersen SA, Whitaker H, Goodenough P. Sleeping body temperatures in 3-4 month old infants. Arch Dis Child 1989;64:596-9.

5 Wright P, Macleod HA, Cooper MJ. Waking at night: the effect of early feeding experience. Child Care Health Dev 1983;9:309-19. 